\title{
Primary laryngeal lymphangioma
}

INSERM

\section{Source}

INSERM. (1999). Orphanet: an online rare disease and orphan drug data base. Primary laryngeallymphangioma. ORPHA:137926

Primary laryngeal lymphang ioma is a rare, benign, cong enital malformation of the lymphatic system characterized by a polypoidal, variable-sized, soft tissue mass located in the larynx. Most lesions manifest by the 2 nd year of life and, depending on the size, patients may present with changes in voice, dysphagia, stridor, airway obstruction and/or respiratory distress. Cystic hygroma of the neck is frequently associated. 